\title{
Nickel doping effect on the structural and optical properties of indium sulfide thin films by SILAR
}

https://doi.org/10.1515/chem-2018-0089

received January 22, 2018; accepted April 13, 2018.

\begin{abstract}
Undoped and nickel doped indium sulfide $\left(\mathrm{In}_{2} \mathrm{~S}_{3}: \mathrm{Ni}\right)$ thin films have been deposited on indium tin oxide (ITO) coated glass substrates by successive ionic layer adsorption and reaction (SILAR) method. The doping concentration of $\mathrm{Ni}$ has been adjusted as 4\%, 5\% and $6 \%$ (in molar ratio of nickel ions to indium ions). The effects of Ni doping on the structural, morphological, compositional and optical properties of the $\mathrm{In}_{2} \mathrm{~S}_{3}$ thin films are investigated. The x-ray diffraction patterns show that deposited film has cubic structure with amorphous nature of $\mathrm{In}_{2} \mathrm{~S}_{3}$ and its crystallinity deteriorates with increasing doping concentration. The SEM measurements show that the surface morphology of the films is affected from the $\mathrm{Ni}$ incorporation. The direct band gap of the films decreases from $2.33 \mathrm{eV}$ to $1.61 \mathrm{eV}$ with increasing $\mathrm{Ni}$ dopant. Energy dispersive x-ray spectroscopy (EDS) has been used to evaluate the chemical composition and shown that $\mathrm{S} /(\mathrm{Ni}+\mathrm{In})$ ratio in films decreases from 1.18 to 0.40 with $\mathrm{Ni}$ content. Optical properties of the films have been performed by a UV-Vis spectrophotometer. The direct band gap of the films decreases from $2.33 \mathrm{eV}$ to $1.61 \mathrm{eV}$ with increasing Ni dopant. Moreover, optical parameters of the films such as refractive index $(n)$, extinction coefficient $(k)$, real $\left(\varepsilon_{1}\right)$ and imaginary $\left(\varepsilon_{2}\right)$ parts of dielectric constant have been determined by using absorbance and transmittance spectra. The investigations showed that the Ni doping has a significant effect on the physical properties of SILAR produced $\operatorname{In}_{2} \mathrm{~S}_{3}$ thin films.
\end{abstract}

Keywords: doping; thin films; optical constant; growth from solutions.

\footnotetext{
*Corresponding author: Fatma Göde, Department of Physics, Mehmet Akif Ersoy University, 15030 Burdur, Turkey, E-mail: ftmgode@gmail.com

Serdar Ünlü: Department of Physics, Mehmet Akif Ersoy University, 15030 Burdur, Turkey
}

\section{Introduction}

Indium sulfide $\left(\operatorname{In}_{2} \mathrm{~S}_{3}\right)$ as a III-VI group semiconductor compound with $\alpha$ (cubic), $\beta$ (tetragonal) and $y$ (trigonal) crystalline phases is an interesting material because of its remarkable properties such as stability, transparency, photoconductive nature, large band gap changing between $2.10 \mathrm{eV}$ [1] and $3.91 \mathrm{eV}$ [2], n-type conductivity [3] and low hazard material compared with cadmium sulfide, cadmium selenide [4], and cadmium telluride. Among these three crystalline phases, $\beta-\operatorname{In}_{2} \mathrm{~S}_{3}$ is the most stable one at room temperature. It is an ideal material used as a layer in $\mathrm{CuInS}_{2}$ (CIS), $\mathrm{Cu}(\mathrm{In}, \mathrm{Ga}) \mathrm{Se}_{2}$ (CIGSe), and CdTebased thin film solar cells [5]. Many researchers have been trying to tune the optical and electrical properties of $\operatorname{In}_{2} \mathrm{~S}_{3}$ by doping thin films for thin film solar cells applications. It is well known that metal dopant acts as electron donors in semiconductor thin films [6] and leads to more electrons available in the valence band.

In the previous work, we deposited $\operatorname{In}_{2} \mathrm{~S}_{3}$ thin films with different complex agent volume, triethanolamine (TEA), on microscope glass substrates at room temperature using the chemical bath deposition technique (CBD) [7]. There are many works on $\operatorname{In}_{2} \mathrm{~S}_{3}$ thin films doped with elements such as Sn [8], Co [9], Al [10], As, Sb or $\mathrm{Bi}$ [11], $\mathrm{Na}$ [12], $\mathrm{Cu}$ [13] and $\mathrm{Ag}$ [14]. However, there is no attempt on nickel doping of the $\operatorname{In}_{2} \mathrm{~S}_{3}$ thin films. In this work, undoped and Ni doped indium sulphide $\left(\operatorname{In}_{2} \mathrm{~S}_{3}: \mathrm{Ni}\right)$ thin films have been synthesized on indium tin oxide (ITO) coated glass substrates for the first time. The present work is focused on the changes in the structural, morphological, compositional and optical properties of the $\operatorname{In}_{2} \mathrm{~S}_{3}$ thin film when doped with Ni dopants. Undoped and Ni doped films have been synthesized using a simple and inexpensive SILAR technique which provides easy coating of the samples at room temperature $[15,16]$. In this technique, thin films are obtained by dipping substrate into separately placed cationic and anionic precursors, and then rinsing with deionized water after each immersion. The deposition rate and the thickness of the 
Table 1: Preparation conditions of In S :Ni thin films.

\begin{tabular}{llllllll}
\hline Material & Film Thickness $(\mathrm{nm})$ & {$[\mathrm{Ni}] /[\mathrm{In}](\%)$} & $\mathrm{pH}$ & & SILAR cycle & Dipping time (s) & Rinsing time (s) \\
& & & In & S & & & \\
\hline $\ln _{2} \mathrm{~S}_{3}: \mathrm{Ni}$ & 444 & 0 & 3.92 & 10.63 & 70 & 40 & 40 \\
$\ln _{2} \mathrm{~S}_{3}: \mathrm{Ni}$ & 395 & 4 & 4.03 & 10.62 & 75 & 40 & 40 \\
$\ln _{2} \mathrm{~S}_{3}: \mathrm{Ni}$ & 360 & 5 & 4.02 & 10.62 & 75 & 40 & 40 \\
$\ln _{2} \mathrm{~S}_{3}: \mathrm{Ni}$ & 317 & 6 & 4.03 & 10.62 & 75 & 40 & 40 \\
\hline
\end{tabular}

film may be easily controlled by changing the deposition cycles of SILAR.

\section{Experimental Details}

The $\mathrm{In}_{2} \mathrm{~S}_{3}$ :Ni thin films have been deposited on indium tin oxide (ITO) coated glasses with sheet resistances of 9.5 $\Omega$ /square $(76 \mathrm{~mm} \times 26 \mathrm{~mm} \times 1 \mathrm{~mm})$ at room temperature by SILAR method. For the deposition of these films, the concentration of nickel ions is adjusted by controlling the quantity of nickel chloride in the mixture, varying as $0 \%, 4 \%, 5 \%$ and $6 \%$ (in molar ratio of nickel ions to indium ions). Before the deposition, the substrates have been initially washed by detergent, boiled in deionized water, and cleaned in methanol, acetone and deionized water for $10 \mathrm{~min}$ sequentially. Following air drying, the deposition of $\operatorname{In}_{2} \mathrm{~S}_{3}$ :Ni thin films were carried out at room temperature. The ITO substrate was immersed in cation precursor solution, containing $0.1 \mathrm{M}$ indium (III) acetate [In( $\left.\mathrm{CH}_{3} \mathrm{COO}\right)_{3}$; Merck; 99.99\% purity; $\left.\mathrm{pH} \sim 4.02\right]$ and $0.1 \mathrm{M}$ nickel (II) chloride ( $\mathrm{NiCl}_{2}+6 \mathrm{H}_{2} \mathrm{O}$; Merck; ACS. Reag.) for $40 \mathrm{~s}$, and then rinsed with deionized water for $40 \mathrm{~s}$ before it was immersed in solutions containing $0.05 \mathrm{M}$ sodium thiosulfate $\left[\mathrm{Na}_{2} \mathrm{~S}_{2} \mathrm{O}_{3} 5 \mathrm{H}_{2} \mathrm{O}\right] ; 99.5 \%$ - 100.5\% purity; $\mathrm{pH} \sim$ 10.62] for additional $40 \mathrm{~s}$. The substrate was rinsed again with deionized water for $40 \mathrm{~s}$ to remove the unreacted ions. By repeating above SILAR steps for 70 times and 75 times for undoped and doped films respectively, thin film of $\operatorname{In}_{2} \mathrm{~S}_{3}$ :Ni was deposited on ITO substrate.

XRD patterns were carried out using $\mathrm{x}$-ray diffractometer with CuKa radiation (XRD, Bruker/AXS-D8, $\lambda=1.5406 \AA$ ) in the $2 \theta$ range from $20^{\circ}$ to $70^{\circ}$, whileurface morphology was studied by scanning electron microscope (SEM, EVO40-LEO). The elemental composition of the films wasexamined using energy dispersive $\mathrm{x}$-ray spectroscopy (EDS) attached to the SEM. For the optical transmittance measurements, a Perkin Elmer Lambda $4 \mathrm{~S}$ UV-Vis spectrophotometer in the wavelength range of 400-1100 nm at room temperature has been used. Film thicknesses $(t)$ were determined gravimetrically with a precision microbalance by assuming the density of bulk $\mathrm{In}_{2} \mathrm{~S}_{3}$ as $4.845 \mathrm{~g} \mathrm{~cm}^{-3}$. Film thickness shows a reduction with increasing Ni concentration as seen in Table 1.

Ethical approval: The conducted research is not related to either human or animals use.

\section{Results and Discussions}

Figure 1 shows the diffraction patterns of ITO substrate and the $\mathrm{In}_{2} \mathrm{~S}_{3}$ :Ni thin films. Deposited films are amorphous in nature. When compared with the standard $2 \theta$ and $d$ values, it can be concluded that the obtained film is cubic $\mathrm{In}_{2} \mathrm{~S}_{3}$ structure (JCPDS card no. 65-0459). As can be seen in Figure 1, the substrate effect is more dominant in the films deposited at Ni concentration of $0 \%$ and $4 \%$. However, the crystallinity of the film deteriorates more with increasing $\mathrm{Ni}$ incorporation and results with disappearing of diffraction peaks coming from substrate in the film deposited at $6 \%$ Ni dopant. Our XRD results are in agreement with the literature [13] and [17] in which Mane et al. reported cubic structure with amorphous nature of $\operatorname{In}_{2} \mathrm{~S}_{3}$ films on glass substrates using SILAR method.

The surface morphology of ITO substrate and $\mathrm{In}_{2} \mathrm{~S}_{3}: \mathrm{Ni}$ thin films are shown in Figure 2. As can be seen, the surface of the films shows granular structure with cracks.

The compositional analysis of $\operatorname{In}_{2} \mathrm{~S}_{3}$ :Ni thin films was performed by EDS and the results are listed in Table 2. The EDS results confirm the presence of $\mathrm{O}$, In, S and Ni elements in the synthesized films. It can be seen that the deposited films show excess of oxygen increasing with increasing $\mathrm{Ni}$ content. This is an expected result because of the aqueous solution method used. Kamoun et al. [10] reported that the presence of Al leads to an increment in adsorption of oxygen in the sample. The average ratio for atomic percentage of $\mathrm{S} /$ $(\mathrm{In}+\mathrm{Ni})$ is 1.18 for deposited films and it decreases to a value of 0.40 with increasing Ni dopant.

In order to examine the effect of doping on the optical properties of the films, the absorbance and transmittance 


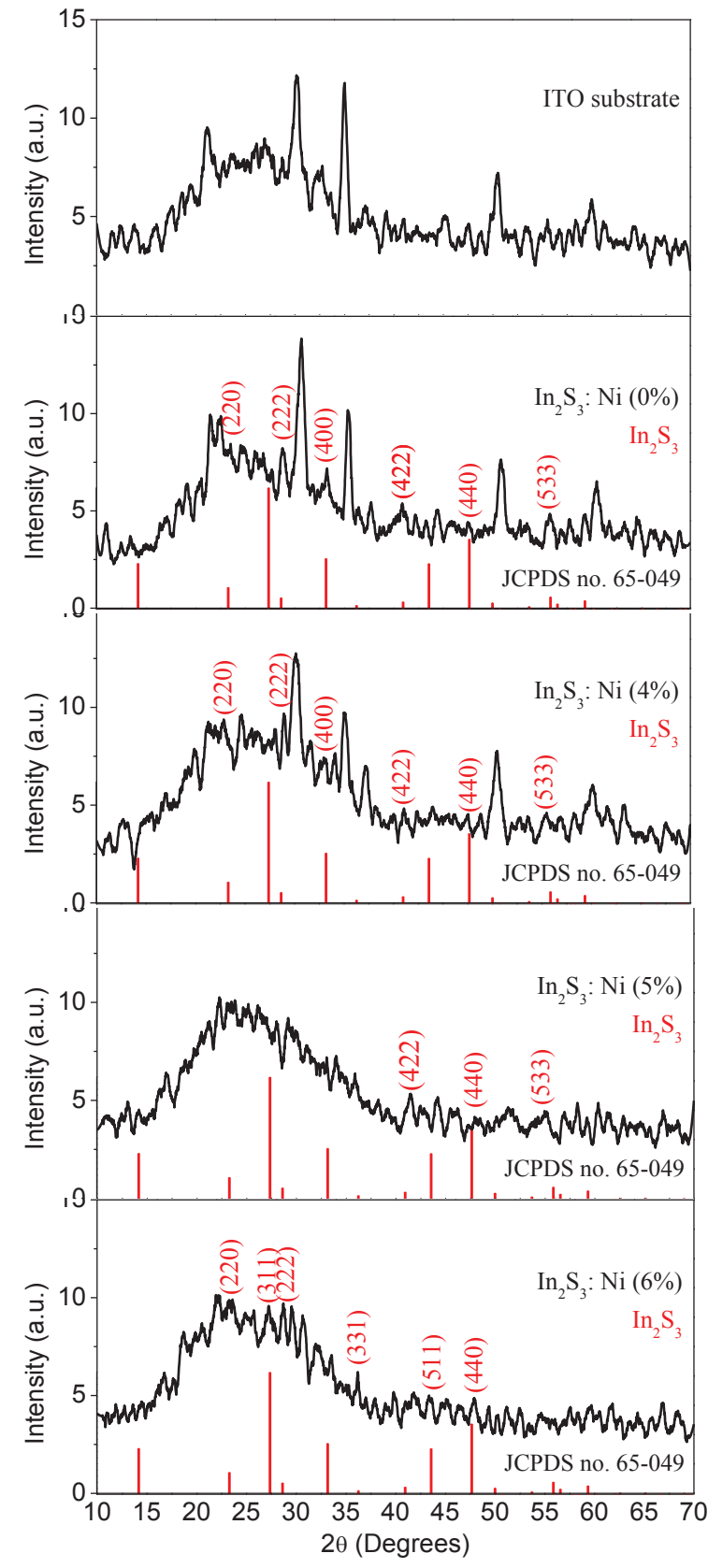

Figure 1: X-ray diffraction patterns of $\ln _{2} \mathrm{~S}_{3}$ :Ni thin films.

measurements were performed at room temperature in the wavelength range 400-1100 $\mathrm{nm}$ as shown in Figure 3. The films exhibit average transmittance between $47 \%$ and $74 \%$ and in the visible region.

In order to calculate the band gap of the films, optical absorption of the films wass studied at room temperature The absorption coefficient $(\alpha)$ of the films was calculated from the normalized transmittance $(T)$ data using the formula:
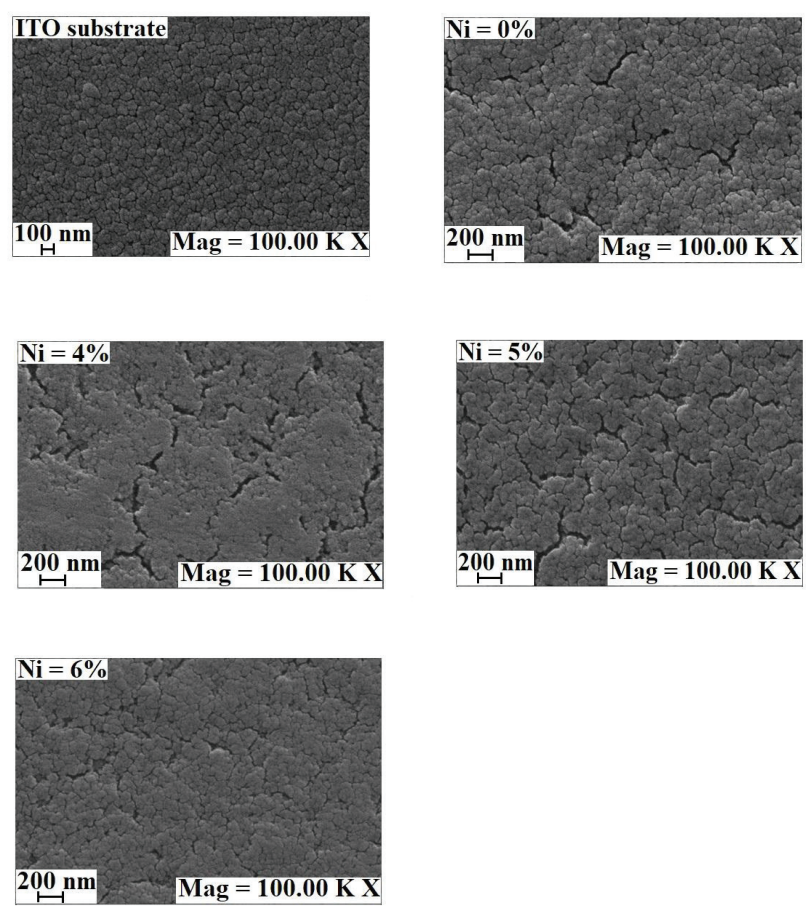

Figure 2: SEM micrographs of $\ln _{2} S_{3}$ :Ni thin films obtained at $100 \mathrm{kx}$ magnification.

Table 2: The EDS analysis of $\ln _{2} \mathrm{~S}_{3}$ :Ni thin films.

\begin{tabular}{|c|c|c|c|c|c|c|}
\hline \multirow[t]{2}{*}{ Material } & \multicolumn{6}{|c|}{ Atomic (at. \%) } \\
\hline & 0 & $\mathbf{S}$ & In & Sn & $\mathrm{Ni}$ & $\mathrm{S} /(\ln +\mathrm{Ni})$ \\
\hline $\mathrm{In}_{2} \mathrm{~S}_{3}: \mathrm{Ni}(0 \%)$ & 77.06 & 10.74 & 9.07 & 3.13 & 0 & 1.18 \\
\hline $\mathrm{In}_{2} \mathrm{~S}_{3}: \mathrm{Ni}(4 \%)$ & 91.74 & 2.98 & 2.15 & 1.53 & 1.60 & 0.79 \\
\hline $\ln _{2} S_{3}: \mathrm{Ni}(5 \%)$ & 91.95 & 2.77 & 2.32 & 1.51 & 1.45 & 0.74 \\
\hline $\mathrm{In}_{2} \mathrm{~S}_{3}: \mathrm{Ni}(6 \%)$ & 92.81 & 1.74 & 3.32 & 1.05 & 1.08 & 0.40 \\
\hline
\end{tabular}

where $t$ is the film thickness. The band gap energy $\left(E_{\mathrm{g}}\right)$ is determined using the Tauc's relation:

$$
\alpha h v=K\left(h v-E_{g}\right)^{n}
$$

where $K$ is a constant depending on transition probability, $h v$ is a photon energy, $E_{\mathrm{g}}$ is the optical band gap, $n$ is an index that characterizes the optical absorption process and theoretically equal to $1 / 2$ for allowed direct transition and 2 for indirect transition [18]. Figure 4 shows the plot of $(a h v)^{2}$ versus photon energy for the films. The optical band 

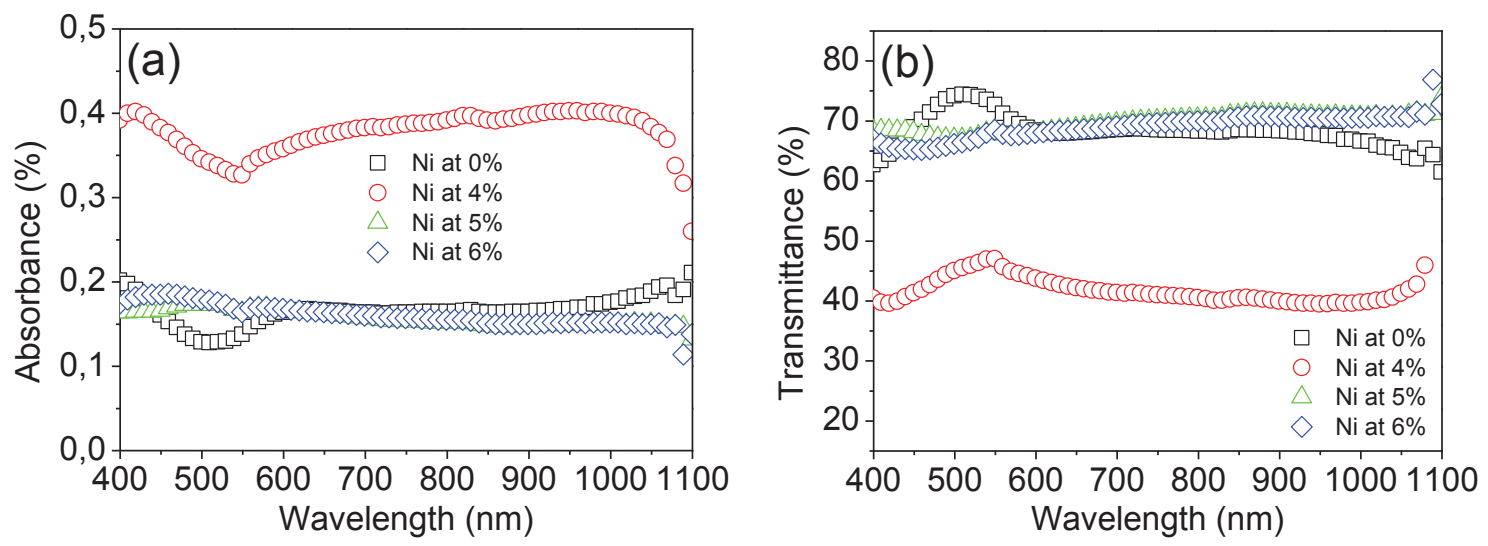

Figure 3: (a) The absorbance and (b) transmittance spectra of $\operatorname{In}_{2} \mathrm{~S}_{3}$ : Ni thin films.

Table 3: Optical parameters for $\ln _{2} S_{3}$ : Ni thin films $(\lambda=600 \mathrm{~nm})$.

\begin{tabular}{llllll}
\hline Materials & $\boldsymbol{E}_{\mathrm{g}}(\mathrm{eV})$ & $\boldsymbol{n}$ & $\boldsymbol{k}$ & $\varepsilon_{1}$ & $\varepsilon_{2}$ \\
\hline $\ln _{2} \mathrm{~S}_{3} \mathrm{Ni}=0 \%$ & 2.33 & 1.84 & 0.18 & 3.35 & 0.64 \\
$\ln _{2} \mathrm{~S}_{3} \mathrm{Ni}=4 \%$ & 1.99 & 2.33 & 0.43 & 5.26 & 2.00 \\
$\ln _{2} \mathrm{~S}_{3} \mathrm{Ni}=5 \%$ & 1.75 & 1.84 & 0.22 & 3.32 & 0.80 \\
$\ln _{2} \mathrm{~S}_{3} \mathrm{Ni}=6 \%$ & 1.61 & 1.82 & 0.25 & 3.26 & 0.91 \\
\hline
\end{tabular}

gaps of the films were determined from the intercept of $(a h v)^{2}$ versus $h v$ curves and obtained $E_{\mathrm{g}}$ values are given in Table 3. The optical band gaps of the films decrease from $2.33 \mathrm{eV}$ to $1.61 \mathrm{eV}$ and shift towards the red region as the $\mathrm{Ni}$ concentration in the films increases, whereas Barreau et al. $[3,12]$ found that the optical band gaps of $\operatorname{In}_{2} \mathrm{~S}_{3}$ thin films, grown by physical vapor deposition, increased from $2.10 \mathrm{eV}$ to $2.95 \mathrm{eV}$ with increasing Na concentration. The shifting in $E_{\mathbf{g}}$ of the films may be attributed to the band shrinkage effect. The narrowing band gap energy is due to the existence of $\mathrm{Ni}$ impurities in the $\mathrm{In}_{2} \mathrm{~S}_{3}$ structure, which induce the introduction of shallow donor levels due to doping. This red shift of $E_{\mathrm{g}}$ could be an increase in carrier concentration with $\mathrm{Ni}$ doping. Moreover, a red shift is attributed to a reduction in $\mathrm{S}$ concentration (an increase in sulfur vacancies), detected from compositional analysis in Table 2, leads to a reduction in the optical energy gap for $\operatorname{In}_{2} \mathrm{~S}_{3}$ : Ni thin films. The measured band gaps are consistent with reported values $2.3 \mathrm{eV}$ [16]. Timoumi et al. [19] reported a band gap changing between $1.61 \mathrm{eV}$ and $2.19 \mathrm{eV}$ for $\mathrm{In}_{2} \mathrm{~S}_{3}$ thin films deposited on glass substrates by vacuum thermal evaporation method.

The transmittance and absorbance data were used to calculate the optical constants such as refractive index $(n)$, extinction coefficient $(k)$, real $\left(\varepsilon_{1}\right)$ and imaginary $\left(\varepsilon_{2}\right)$ parts of dielectric constant. The $n$ is described by the Fresnel formulae [20]:

$$
n=\frac{1+R}{1-R}+\sqrt{\frac{4 R}{(1-R)^{2}}-k^{2}}
$$

where $R$ is the reflectance and $k$ is given by $\alpha \lambda / 4 \pi$. The dependence of $n$ and $k$ on wavelength for the films are shown in Figures 5(a) and (b), respectively and results are listed in Table 3. At $\lambda=600 \mathrm{~nm}$, the $n$ value of deposited films first increases from 1.84 to 2.33 and then decreases to the value of 1.82 with $\mathrm{Ni}$ concentration. The present $n$ values are also in good agreement with the literature for $\operatorname{In}_{2} \mathrm{~S}_{3}$ thin films (1.6-1.84) [21] and (2.5) [22]. Esmaili et al. [13] found the $n$ value between 1.0 and 2.5 for $\operatorname{In}_{2} \mathrm{~S}_{3}: \mathrm{Cu}$ thin films deposited by CBD. The $k$ values are consistent with our previous data (0.33-0.72) [7] but they are lower than Ref. [13] in which $\mathrm{In}_{2} \mathrm{~S}_{3}: \mathrm{Cu}$ thin films were deposited by CBD. At $\lambda=600 \mathrm{~nm}$, the $k$ value varies between 0.18 and 0.43 with the increase in $\mathrm{Ni}$ concentration. The $k$ values are consistent with the reported data obtained by Kaleel et al. [23] in which $\operatorname{In}_{2} \mathrm{~S}_{3}$ :Cu thin films were obtained by spray pyrolysis method.

The $\varepsilon_{1}$ and $\varepsilon_{2}$ were calculated by using Eqs. (4) and (5):

$$
\begin{gathered}
\varepsilon_{1}=n^{2}-k^{2} \\
\varepsilon_{2}=2 n k
\end{gathered}
$$

Figures 5(c) and (d) show the plots of $\varepsilon_{1}$ and $\varepsilon_{2}$, respectively. At $\lambda=600 \mathrm{~nm}$, the $\varepsilon_{1}$ value first increases from 3.35 to 5.26 and then decreases to the value of 3.26 with $\mathrm{Ni}$ concentration. The $\varepsilon_{2}$ value varies between 0.64 and 2.00 as seen in Table 3. Both $\varepsilon_{1}$ and $\varepsilon_{2}$ values are consistent with the previous data $[7,23]$. 

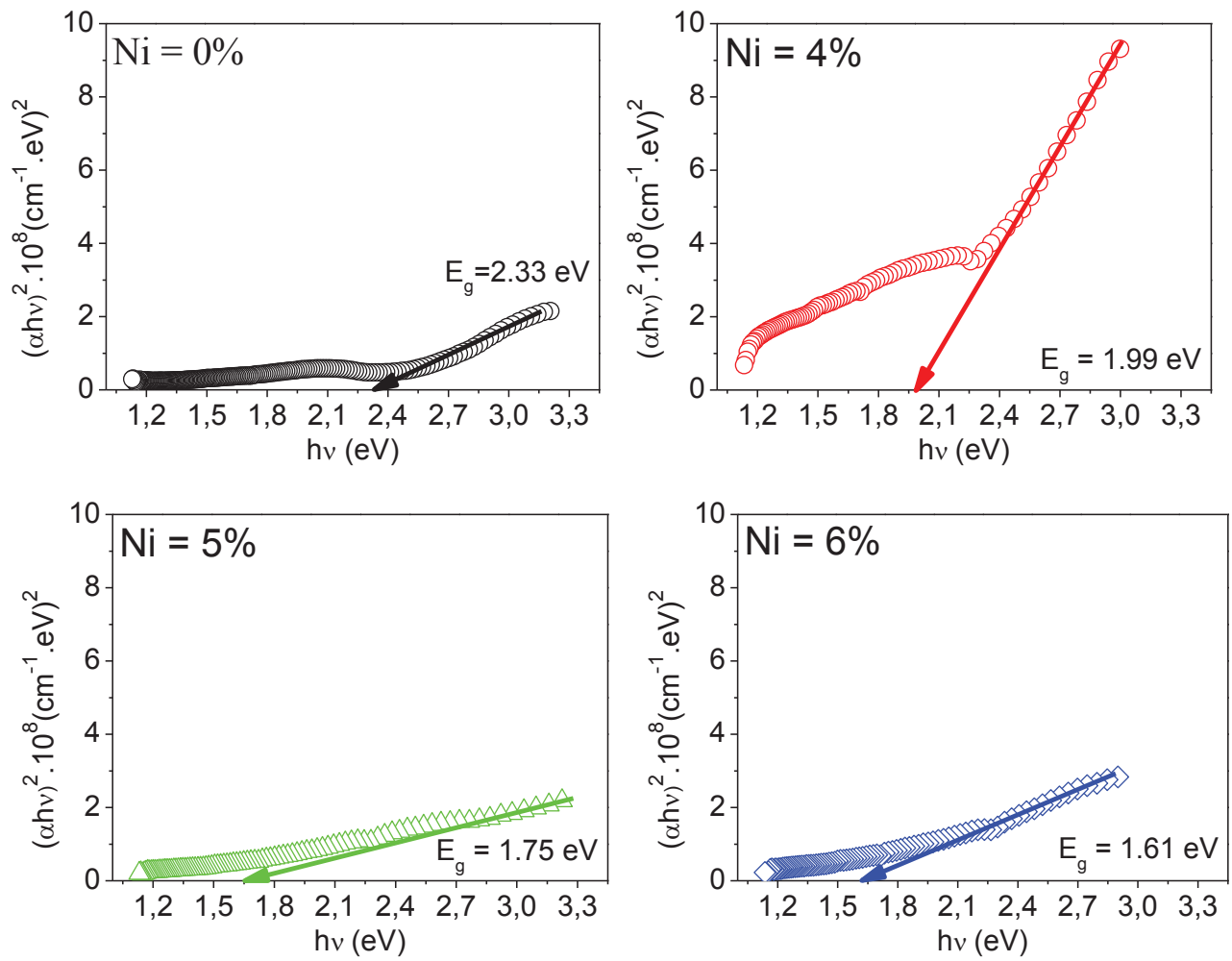

Figure 4: Plot of $(a h v)^{2}$ versus $(h v) \ln _{2} \mathrm{~S}_{3}: \mathrm{Ni}$ thin films.
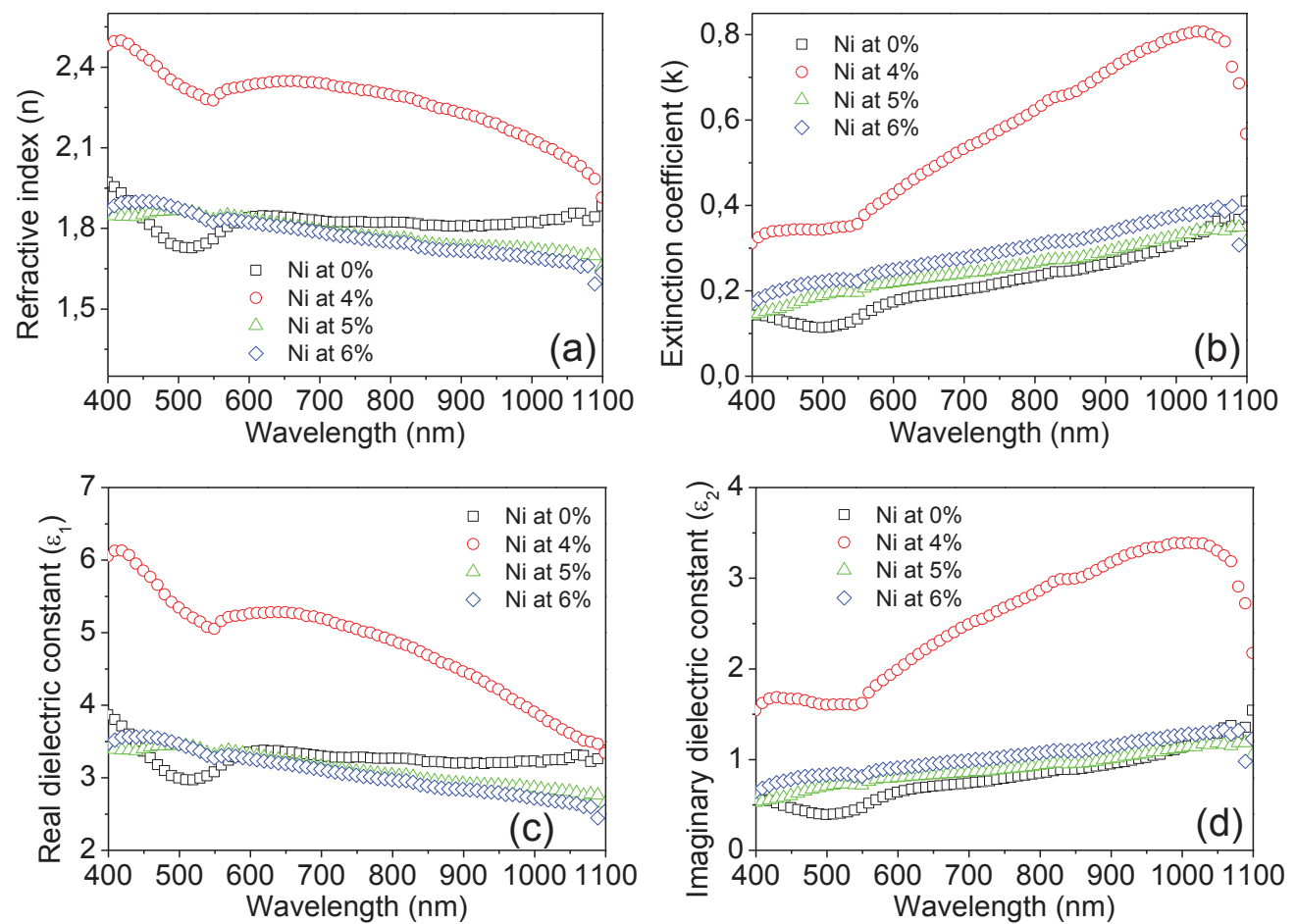

Figure 5: The variation of (a) refractive index, (b) extinction coefficient, (c) real and (d) imaginary dielectric constant for $\ln _{2} \mathrm{~S}_{3}: \mathrm{Ni}$ thin films. 


\section{Conclusions}

$\operatorname{In}_{2} \mathrm{~S}_{3}: \mathrm{Ni}$ thin films are deposited on ITO substrate by SILAR technique. The SILAR is a simple and economic technique and useful for large area thin film depositions with low cost. The effect of Ni dopant on the structural, morphological, optical and electrical properties is studied. The $\mathrm{S} /(\mathrm{In}+\mathrm{Ni})$ ratio in the films decreases from 1.18 to 0.40 with Ni content. The XRD result shows that deposited films have cubic structure with amorphous nature of $\operatorname{In}_{2} \mathrm{~S}_{3}$ and their crystallinity deteriorates with increasing doping concentration. The $E_{\mathrm{g}}$ values of the films are affected from the incorporation of $\mathrm{Ni}$ and resulted a reduction with Ni doping. The optical parameters such as refractive index, extinction coefficient, real and imaginary parts of dielectric constant were determined. These results show that the Ni doping modifies the structural, morphological and optical properties of the $\operatorname{In}_{2} \mathrm{~S}_{3}$ thin films.

Acknowledgement: This work has been supported by the Management Unit of Scientific Research Projects of Mehmet Akif Ersoy University (project no. 0201-NAP-13).

Conflict of interest: Authors state no conflict of interest.

\section{References}

[1] Robles R., Barreau N., Vega A., Marsillac S., Bernède J.C., Mokrani A., Optical properties of large band gap b-In2S3$3 \times 03 \times$ compounds obtained by physical vapour deposition, Opt. Mater., 2005, 27, 647-653.

[2] Zhong Z.Y., Cho E.S., Kwon S.J., Effect of substrate temperatures on evaporated In2S3 thin film buffer layers for $\mathrm{Cu}(\mathrm{In}, \mathrm{Ga}) \mathrm{Se} 2$ solar cells, Thin Solid Films, 2013, 547, 22-27.

[3] Barreau N., Bernède J.C., Marsillac S., Amory C., Shafarman W.N., New Cd-free buffer layer deposited by PVD: In2S3 containing Na compounds, Thin Solid Films, 2003, 431-432, 326-329.

[4] Kariper İ.A., Bağlayan Ö., Göde F., Fabrication and optical characterization of CdSe thin films grown by chemical bath deposition, Acta Phys. Pol. A, 2015, 127(2B), 219-221.

[5] Mughal M.A., Engelken R., Sharma R., Progress in indium (III) sulfide (In2S3) buffer layer deposition techniques for CIS, CIGS, and CdTe-based thin film solar cells, Sol. Energy, 2015, 120, 131-146.

[6] Keio M.E., Kamimura H., Comprehensive semiconductor science and technology, In: Bhattacharya P., Fornari R, Kamimura H. (Eds.), vol. 1, Elsevier, Netherlands, 1989.

[7] Göde F., Kariper I.A., Güneri E., Ünlü S., Effect of complexing agent on the structural, optical and electrical properties of polycrystalline indium sulfide thin films deposited by chemical bath deposition, Acta Phys. Pol. A, 2017, 132(3), 527-530.
[8] Mathew M., Gopinath M., Kartha C.S., Vijayakumar K.P., Kashiwaba Y., Abe T., Tin doping in spray pyrolysed indium sulfide thin films for solar cell applications, Solar Energy, 2010, 84 888-897.

[9] Kim C.D., Lim H., Park H.L., Park H.Y., Kim J.E, Kim H.G., et al., Optical absorption of $\mathrm{Co2}+$ ions in $\ln 2 \mathrm{~S} 3$ thin films, Thin Solid Films, 1993, 224(1,25), 69-73.

[10] Kamoun N., Belgacem S., Amlouk M., Bennaceur R., Bonnet J., Touhari F., et al., Structure, surface composition, and electronic properties of b- $\ln 2 S 3$ and b- In2-xAlxS3, J. Appl. Phys., 2001, 89(5), 2766-2771.

[11] Diehl R., Nitsche R., Vapour and flux growth of g-In2S3, a new modification of insium sesquisulphide, J. Cryst. Growth, 1973, 20(1), 38-46.

[12] Barreau N., Bernede J.C., Deudon C., Brohan L., Marsillac S., Study of the new b-In2S3 containing Na thin films Part I: Synthesis and structural characterization of the material, J. Cryst. Growth, 2002, 241, 4-14.

[13] Esmaili P., Kangarlou H., Savaloni H., Ghorannevis M., Structural, optical and electronic properties of indium sulphide compositions under influence of copper impurity produced by chemical method, Res. Phys., 2017, 7, 3380-3389.

[14] Mathew M., Jayakrishnan R., Ratheesh Kumar P.M., Sudha Kartha C., Vijayakumar K.P., Anomalous behavior of silver doped indium sulfide thin films, J. Appl. Phys., 2006, 100(3), 33504-335018.

[15] Güneri E., Göde F., Çevik S., Influence of grain size on structural and optic properties of PbS thin films produced by SILAR method, Thin Solid Films, 2015, 589, 578-583.

[16] Huerta-Flores A.M., García-Gómez N.A., De la Parra S.M., Sánchez E.M., Comparative study of Sb2S3, Bi2S3, In $2 S 3$ thin film deposition on $\mathrm{TiO} 2$ by successive ionic layer adsorption and reaction (SILAR) method, Mater. Sci. Semicon. Proc., 2015, 37, 235-240.

[17] Mane R.S., Lokhande C.D., Studies on structural, optical and electrical properties of indium sulfide thin films, Mater. Chem. Phys., 2003, 78, 15-17.

[18] Tauc T., Amorphous and Liquid Semiconductors, Plenum Press, New York, 1974.

[19] Timoumi A., Bouzouita H., Brini R., Kanzari M., Rezig B., Optimization of annealing conditions of $\ln 2 \mathrm{~S} 3$ thin films deposited by vacuum thermal evaporation, Appl. Surf. Sci., 2006, 253, 306-310.

[20] Abeles F., (Ed.), Optical Properties of Solids, North-Holland Publishing Company, London, UK, 1972.

[21] John T.T., Kartha C.S., Vijayakumar K.P., Abe T., Kashiwaba Y., Spray pyrolyzed b-In2S3 thin films: Effect of postdeposition annealing, Vacuum, 2006, 80, 870-875.

[22] Wang S.S., Shiou F.J., Tsao C.C., Huang S.W., Hsu C.Y., An evaluation of the deposition parameters for indium sulfide (In2S3) thin films using the Grey-Based Taguchi method, Mat. Sci. Semicon. Proc., 2013, 16, 1879-1887.

[23] Kaleel S.G., Suhail M.H., Yasser F.M., Spray Deposition of Cu: In2S3 thin films, I. J. Emerging Technol. Advanced Eng., 2014, 4(3), 613-622. 